\title{
Mindfulness Meditation, Mental Health, and Health-Related Quality of Life in Chinese Buddhist Monastics
}

\author{
MCF Tsui, JCN To, ATC Lee
}

\begin{abstract}
Objective: To determine associations between mindfulness meditation and mental health and healthrelated quality of life among Buddhist monastics.

Methods: This is a cross-sectional study of Chinese Buddhist monastics aged $\geq 18$ years who practised mindfulness meditation daily. Mental health was assessed by the 12-item General Health Questionnaire (GHQ-12), whereas health-related quality of life was assessed by the 12-item Short Form Health Survey (SF-12). The number of years and the average daily amount of time spent in mindfulness meditation were collected.

Results: 47 monastics completed the interview. They practised mindfulness meditation for a mean of 7.3 years, 1.1 hours per day. Both the number of years $(\beta=-0.48, p=0.03)$ and amount of daily practice $(\beta=-0.53, p<0.001)$ of mindfulness meditation were associated with the GHQ-12 score, after adjusting for age, sex, education, and years of being a monastic. Only the amount of daily practice $(\beta=0.44$, $p=0.004$ ) was associated with the mental component summary of SF-12. Neither was associated with the physical component summary of SF-12.

Conclusions: Among Chinese Buddhist monastics who practise daily mindfulness meditation, spending more time each day and having longer years of practice were associated with better mental health.
\end{abstract}

Key words: Buddhism; Meditation; Mental health; Mindfulness; Quality of life

Mark CF Tsui, MSc, Department of Psychiatry, The Chinese University of Hong Kong, Hong Kong SAR, China \& TSz Shan Monastery, Hong Kong SAR, China Joanna CN To, MExpArtsTh, Tsz Shan Monastery, Hong Kong SAR, China Allen TC Lee, MBChB, Department of Psychiatry, The Chinese University of Hong Kong, Hong Kong SAR, China

Address for correspondence: Allen Lee, Department of Psychiatry, G/F, MultiCentre, Tai Po Hospital, Tai Po, New Territories, Hong Kong SAR, China. Email:allenlee@cuhk.edu.hk

Submitted: 10 July 2019 Accepted: 26 November 2019

\section{Introduction}

Mindfulness meditation involves bringing one's attention consciously and non-judgmentally to the present reality, ${ }^{1,2}$ and is a traditional practice among Buddhist monastics. ${ }^{3}$ Mindfulness-based stress reduction is useful in improving mental health and health-related quality of life in people with various conditions, ${ }^{4-8}$ probably as a result of improved emotional, cognitive, physiological, and immune responses to stress. ${ }^{9-11}$ However, it remains unclear whether a linear relationship exists between longer duration of mindfulness meditation and better health outcomes. In addition, mindfulness meditation takes time to master, and the level of experience is likely a determinant of health outcomes. The mindfulness training conducted in previous randomised controlled trials was usually brief, lasting for weeks to at most months. Variations in the length of training may explain differences in outcome across studies, ${ }^{12}$ although shorter programmes are not necessarily less effective. ${ }^{13,14}$ It is of interest to examine whether the level of experience is associated with mental health and health-related quality of life in a cohort with long-standing practice of mindfulness meditation.

In the present study, we interviewed Buddhist monks and nuns living in a monastery in Hong Kong. The aim of this study was to examine whether the amount of daily practice, the number of years of practice, and the resultant accumulated level of experience in mindfulness meditation were associated with mental health and health-related quality of life. We hypothesised that more meditation practice was associated with better mental health and quality of life. The findings might provide evidence that regular long-term practice of mindfulness meditation is beneficial to mental health and quality of life.

\section{Methods}

This cross-sectional observational study was approved by the Survey and Behavioural Research Ethics Committee of the Chinese University of Hong Kong and conducted between 13 November 2017 and 28 February 2018. The secretary general and abbot of an orthodox Chinese Buddhist monastery were explained about the nature and purpose of the study. Written informed consent was obtained from participants prior to the interview. Full-time 
Chinese Buddhist monastics aged $\geq 18$ years living in the monastery who practised mindfulness meditation daily since they became a monastic were included. Those who had already practised mindfulness meditation prior to becoming a monastic or those who had no regular practice of mindfulness meditation were excluded. All participants practised mindfulness in the form of sitting meditation in the early morning and, depending on their roles and duties in the monastery, spent varying amount of time on walking meditation and chanting for the rest of the day.

The Chinese version of the 12-item General Health Questionnaire (GHQ-12) was used to screen for the presence of any common psychiatric disorder. The maximum score is 36; higher scores indicate poorer mental health. It has good reliability and validity in the Chinese populations. ${ }^{15}$

The Chinese version of the 12-item Short Form Health Survey (SF-12) was used to assess the health-related quality of life. It covers eight domains: physical functioning, role-physical, bodily pain, general health, vitality, social functioning, role-emotion, and mental health. The first four and the last four contribute to physical component summary (PCS) and mental component summary (MCS), respectively. It has good reliability and validity. ${ }^{16}$ We used the Optum SF-12v2, with PCS and MCS calculated using a norm-based scoring method, with higher scores indicating better health-related quality of life.

Sociodemographic data were collected, including age, sex, educational level, age and years of becoming a monastic, and the average amount of time spent in mindfulness meditation every day.

Sample size calculation was performed using the Power and Precision software (version 3.0, Biostat). To our knowledge, no prior study has examined mindfulness meditation and mental health in the Chinese Buddhist monastics. Based on a previous cross-sectional study that compared the mental health and health-related quality of life between Zen meditation trainees with 1 year and 3 years of training in Japan, ${ }^{17}$ we estimated that a sample size of 40 participants would yield at least $80 \%$ power, with alpha set at 0.05 .

Statistical analysis was conducted using SPSS (Windows version 24; IBM Corp, Armonk [NY], US). Pearson correlation analysis was performed to determine whether factors relating to mindfulness meditation (starting age of practice, number of years of practice, and amount of daily practice) were correlated with the scores of GHQ-12 and SF-12. The level of statistical significance was set at $\mathrm{p}<0.05$ (2-tailed).

Sensitivity analyses were performed to identify any age, sex, and educational differences in the GHQ-12 and SF-12 scores, using correlation test, independent $t$-test, and ANOVA, respectively, and to examine correlations between age and years of being monastics and the GHQ-12 and SF-12 scores.

Multiple linear regression analysis was performed to examine whether years of practice and amount of daily practice of mindfulness meditation were independently associated with the GHQ-12 and SF-12 scores, after adjustment for co-variables (age, sex, educational level, and years of being a monastic). The number of years of practice and the amount of daily practice of mindfulness meditation were treated as predictors, whereas the GHQ-12 and SF-12 scores were treated as dependent variables.

To determine whether the level of experience in mindfulness meditation is associated with the GHQ-12 and SF-12 scores, comparisons of the scores were made between those with and without $\geq 0.5$ hour of mindfulness meditation (the 25 th percentile) for $\geq 3$ years (the 25 th percentile), $\geq 0.5$ hour of mindfulness meditation (the 25 th percentile) for $\geq 6$ years (the 50 th percentile), $\geq 1$ hour of mindfulness meditation (the 50th percentile) for $\geq 3$ years (the 25 th percentile), and $\geq 1$ hour of mindfulness meditation (the 50 th percentile) for $\geq 6$ years (the 50 th percentile), using the independent $t$-test. The scores were also compared across the above groups using the ANOVA.

\section{Results}

Of 73 monastics invited, 47 completed the interview (Figure). Most of them were female $(n=35)$, with secondary educational level or above. The mean age of participants was $37.7 \pm 10.0$ years, their mean years of being monastics was $11.3 \pm 7.0$ years, their mean years of practice of mindfulness meditation was $7.3 \pm 6.4$ years, and their average amount of practice per day was $1.1 \pm 0.6$ hours. Their mean GHQ-12 score was 9.6 \pm 5.8 , with mean PCS of $51.7 \pm 6.5$ and mean MCS of $48.4 \pm 6.9$ (Table 1).

Among different factors of mindfulness meditation, only the amount of daily practice was correlated to the GHQ-12 score $(r=-0.41, \mathrm{p}=0.004)$ and the MCS score ( $r=0.46, \mathrm{p}=0.001)$ [Table 2]. None of the factors was correlated to the PCS score. Other sociodemographic variables (age, sex, educational level, and age and years of being a monastic) were not correlated to the GHQ-12, PCS, or MCS scores (Table 3).

Multiple linear regression analysis showed that both the amount of daily practice $(\beta=-0.53, \mathrm{p}<0.001)$ and the number of years of practice $(\beta=-0.48, p=0.03)$ of mindfulness meditation were associated with the GHQ-12 score $\left(\mathrm{R}^{2}=0.31, \mathrm{p}=0.02\right)$, after adjusting for age, sex,

73 monastics were invited

26 were excluded:

7 declined to be interviewed

5 lost contact after invitation

4 had difficulty in communication

10 did not have regular mindfulness meditation

47 participants were included 
educational level, and years of being a monastic. Whereas only the amount of daily practice $(\beta=0.44, \mathrm{p}=0.004)$ was associated with the MCS score $\left(\mathrm{R}^{2}=0.27, \mathrm{p}=0.04\right)$, after adjusting for the co-variates.

The overall regression model showed no association between PCS score and the amount of daily practice and

Table 1. Sociodemographic characteristics of participants.

\begin{tabular}{|c|c|}
\hline Characteristic & Value $^{*}$ \\
\hline Age, years & $37.7 \pm 10.0$ \\
\hline \multicolumn{2}{|l|}{ Sex } \\
\hline Male & $12(25.5)$ \\
\hline Female & $35(74.5)$ \\
\hline \multicolumn{2}{|l|}{ Educational level } \\
\hline Primary & $1(2.1)$ \\
\hline Secondary & $27(57.4)$ \\
\hline College or university & $12(25.5)$ \\
\hline Post-graduate & $7(14.9)$ \\
\hline Age of being a monastic, $y$ & $26.3 \pm 9.6$ \\
\hline Years of being a monastic & $11.3 \pm 7.0$ \\
\hline \multicolumn{2}{|l|}{ Mindfulness meditation } \\
\hline Starting age of practice & $30.4 \pm 9.8$ \\
\hline Years of practice & $7.3 \pm 6.4$ \\
\hline $\begin{array}{l}\text { Average amount of time of practice per } \\
\text { day, hours }\end{array}$ & $1.1 \pm 0.6$ \\
\hline 12-item General Health Questionnaire score & $9.6 \pm 5.8$ \\
\hline \multicolumn{2}{|l|}{ 12-item Short Form Health Survey } \\
\hline Physical component summary & $51.7 \pm 6.5$ \\
\hline Physical functioning & $93.1 \pm 14.5$ \\
\hline Role-physical & $72.3 \pm 19.5$ \\
\hline Bodily pain & $73.9 \pm 25.5$ \\
\hline General health & $62.9 \pm 29.4$ \\
\hline Mental component summary & $48.4 \pm 6.9$ \\
\hline Vitality & $64.4 \pm 26.4$ \\
\hline Social functioning & $84.0 \pm 17.6$ \\
\hline Role-emotion & $67.6 \pm 21.0$ \\
\hline Mental health & $72.6 \pm 16.0$ \\
\hline
\end{tabular}

* Data are presented as No. (\%) of participants or mean \pm standard deviation the number of years of practice $\left(\mathrm{R}^{2}=0.24, \mathrm{p}=0.07\right)$, after controlling for the co-variates.

In comparisons of the GHQ-12, PCS, and MCS scores among monastics with different levels of experience in mindfulness meditation, the GHQ-12 score was lower in those with higher level of experience in mindfulness meditation (Table 4). The GHQ-12 score was lower in those with the most experience ( $\geq 1$ hour per day for $\geq 6$ years) than those with the least experience $(<0.5$ hour per day for $<3$ years) [5.7 vs 12.3, p =0.03]. The difference in GHQ-12 score was most significant between those with and without $\geq 1$ hour per day for $\geq 3$ years $(6.7$ vs $11.8, p=0.001)$. A similar trend was observed for PCS and MCS; those with more experience in mindfulness meditation had higher scores but not significantly.

\section{Discussion}

To our knowledge, this is the first study that examined the association of the amount of practice of mindfulness meditation with mental health and health-related quality of life among Buddhist monastics. Both the amount of daily practice and the number of years of practice were associated with mental health, whereas only the former was associated with mental health-related quality of life, but neither was associated with physical health-related quality of life. The association was independent of the age of participants and years of being a monastic. These findings suggest that mindfulness meditation is beneficial to people of all ages, and it is never too late to start the practice. Furthermore, those with higher level of experience in mindfulness meditation had a significantly lower GHQ-12 score. These suggest that maintaining regular practice of mindfulness meditation might be useful in promoting better mental health.

Our findings are consistent with the literature that mindfulness is useful in improving mental health. However, previous studies were often short in duration and brief in mindfulness training. ${ }^{12}$ In the present study, participants were Buddhist monastics who have years of experience in mindfulness meditation and practise for an average of an hour a day. This cohort enables better understanding of potential benefits of regular long-term practice of mindfulness meditation and the association between the

Table 2. Correlations between mindfulness meditation and mental health and health-related quality of life

\begin{tabular}{|lccc|}
\hline Mindfulness meditation & $\begin{array}{c}\text { 12-item } \\
\text { General Health } \\
\text { Questionnaire }\end{array}$ & $\begin{array}{c}\text { Physical component } \\
\text { summary }\end{array}$ & $\begin{array}{c}\text { Mental component } \\
\text { summary }\end{array}$ \\
\cline { 3 - 5 } Starting age of practice & $r=0.02, \mathrm{p}=0.89$ & $r=-0.27, \mathrm{p}=0.06$ & $r=0.14, \mathrm{p}=0.34$ \\
\hline Years of practice & $r=-0.17, \mathrm{p}=0.27$ & $r=0.09, \mathrm{p}=0.54$ & $r=-0.13, \mathrm{p}=0.38$ \\
\hline Average amount of time of practice per day & $r=-0.41, \mathrm{p}=0.004$ & $r=0.25, \mathrm{p}=0.09$ & $r=0.46, \mathrm{p}=0.001$ \\
\hline
\end{tabular}


Table 3. Associations between sociodemographic variables and mental health and health-related quality of life

\begin{tabular}{|lccc|}
\hline Variable & $\begin{array}{c}\text { 12-item General } \\
\text { Health Questionnaire }\end{array}$ & \multicolumn{2}{c|}{ 12-item Short Form Health Survey } \\
\cline { 3 - 4 } & & $\begin{array}{c}\text { Physical component } \\
\text { summary }\end{array}$ & $\begin{array}{c}\text { Mental component } \\
\text { summary }\end{array}$ \\
Age & $r=-0.09, \mathrm{p}=0.56$ & $r=-0.21, \mathrm{p}=0.16$ & $r=0.05, \mathrm{p}=0.72$ \\
\hline Sex & $\mathrm{p}=0.50$ & $\mathrm{p}=0.21$ & $\mathrm{p}=0.07$ \\
Male $(\mathrm{n}=12)$ & $10.6 \pm 5.8$ & $49.7 \pm 5.3$ & $51.5 \pm 5.2$ \\
Female $(\mathrm{n}=35)$ & $9.3 \pm 5.9$ & $52.4 \pm 6.8$ & $47.3 \pm 7.1$ \\
\hline Education & $\mathrm{p}=0.15$ & $\mathrm{p}=0.51$ & $\mathrm{p}=0.16$ \\
Primary $(\mathrm{n}=1)$ & 16 & 53.8 & 35.3 \\
Secondary $(\mathrm{n}=27)$ & $9.0 \pm 6.1$ & $52.9 \pm 6.8$ & $48.3 \pm 6.8$ \\
College or university $(\mathrm{n}=12)$ & $8.1 \pm 3.8$ & $49.9 \pm 6.2$ & $50.6 \pm 5.6$ \\
Post-graduate $(\mathrm{n}=7)$ & $13.4 \pm 6.4$ & $50.2 \pm 5.8$ & $46.9 \pm 7.9$ \\
\hline Age of being a monastic & $r=-0.08, \mathrm{p}=0.59$ & $r=-0.11, \mathrm{p}=0.45$ & $r=0.08, \mathrm{p}=0.62$ \\
\hline Years of being a monastic & $r=-0.01, \mathrm{p}=0.93$ & $r=-0.14, \mathrm{p}=0.34$ & $r=-0.03, \mathrm{p}=0.86$ \\
\hline
\end{tabular}

Table 4. Comparison of scores of mental health and health-related quality of life among monastics with different levels of experience in mindfulness meditation

\begin{tabular}{|cccc|}
\hline Level of experience in & $\begin{array}{c}\text { 12-item General } \\
\text { mindfulness meditation }\end{array}$ & \multicolumn{2}{c|}{ 12-item Short Form Health Survey } \\
\cline { 3 - 4 } & & $\begin{array}{c}\text { Physical component } \\
\text { summary }\end{array}$ & $\begin{array}{c}\text { Mental component } \\
\text { summary }\end{array}$ \\
$\geq 0.5$ hour/day for $\geq 3$ years & $\mathrm{p}=0.13$ & $\mathrm{p}=0.99$ & $\mathrm{p}=0.37$ \\
No $(\mathrm{n}=12)$ & $12.3 \pm 7.4$ & $51.7 \pm 7.3$ & $46.7 \pm 7.8$ \\
Yes $(\mathrm{n}=35)$ & $8.7 \pm 5.0$ & $51.8 \pm 6.3$ & $50.0 \pm 6.6$ \\
\hline$\geq 0.5$ hour/day for $\geq 6$ years & $\mathrm{p}=0.25$ & $\mathrm{p}=0.43$ & $\mathrm{p}=0.66$ \\
No $(\mathrm{n}=23)$ & $10.6 \pm 6.0$ & $51.0 \pm 6.4$ & $48.9 \pm 6.9$ \\
Yes $(\mathrm{n}=24)$ & $8.6 \pm 5.6$ & $52.5 \pm 6.6$ & $48.0 \pm 7.0$ \\
\hline$\geq 1$ hour/day for $\geq 3$ years & $\mathrm{p}=0.001$ & $\mathrm{p}=0.35$ & $\mathrm{p}=0.003$ \\
No $(\mathrm{n}=27)$ & $11.8 \pm 5.8$ & $51.0 \pm 6.7$ & $45.9 \pm 6.2$ \\
Yes $(\mathrm{n}=20)$ & $6.7 \pm 4.6$ & $52.8 \pm 6.2$ & $51.8 \pm 6.4$ \\
\hline$\geq 1$ hour/day for $\geq 6$ years & $\mathrm{p}=0.02$ & $\mathrm{p}=0.03$ & $\mathrm{p}=0.15$ \\
No $(\mathrm{n}=36)$ & $10.8 \pm 5.4$ & $50.7 \pm 6.5$ & $47.5 \pm 6.5$ \\
Yes $(\mathrm{n}=11)$ & $5.7 \pm 5.7$ & $55.3 \pm 5.3$ & $51.3 \pm 7.5$ \\
\hline Overall & $\mathbf{p}=\mathbf{0 . 0 3}$ & $\mathbf{p}=\mathbf{0 . 3 0}$ & $\mathbf{p}=\mathbf{0 . 0 5}$ \\
\hline
\end{tabular}

amount of practice and mental health and health-related quality of life.

Previously, one study examined meditation and mental health in the Indian monastics,$^{18}$ and another examined Zen training and mental health and quality of life in Japanese monk trainees. ${ }^{17}$ However, it was uncertain if the type of meditation involved mindfulness meditation. The case mix in the first study was heterogeneous, with monks and nuns recruited from different sources, including a volunteer centre, whereas the cohort in the second study was male trainees, with a mean training of 2.6 years only.

Our findings suggest that spending more time in mindfulness meditation is associated with better mental health, but care should be taken when generalising our findings to the community or clinical cohorts. The lifestyle of monastics is very different from that of the general populations. Monastics are vigorous vegetarian and are likely to be mindful in daily activities including eating, chanting, praying, and even walking. Although they have a simple and structured life that does not aim to pursue 
fame or fortune, they have specific roles and duties in the monastery, have little free time, and need to be highly disciplined. Further studies are needed to examine if longstanding practice of mindfulness meditation is beneficial to mental health in the community or clinical populations. In addition, there are different forms of Buddhism and meditative styles, various definitions of mindfulness, and a wide range of mindfulness-based programmes, some of which integrate with components of psychological interventions or modalities of complementary or alternative therapies. ${ }^{1,2,19}$ A meta-analysis concluded that the large heterogeneity of the type of meditation programmes makes comparison of effectiveness difficult, although the evidence suggests a small-to-moderate effect on mood and mental health-related quality of life. ${ }^{12}$ Furthermore, our cohort is unlikely to be representative of the monastic populations because it is a convenient sample from a single monastery. The total number of monastics in Hong Kong is estimated to be around $5000 .{ }^{20}$ Studies with more in-depth assessments of the meditation methods are needed to identify the health benefits of different programmes and the role of each component within a programme.

The present study did not examine the underlying mechanisms of the observed association between spending more time in mindfulness meditation and better mental health. We speculate that more practice improves selfawareness and acknowledgement of one's own thoughts in a non-judgmental manner, reduces rumination on emotion, and increases the likelihood of being more adaptive in functioning in emotionally aroused states, thereby promoting better mental health in the long term. ${ }^{10}$ These are supported by functional neuroimaging studies, which suggest a difference in the neural responses to emotional reactivity between experienced and beginner meditators. Experienced meditators have increased functional connectivity between dorsomedial prefrontal cortex and right inferior parietal lobule (reflecting enhanced conscious awareness of the present moment) and decreased connectivity between dorsomedial prefrontal cortex and left inferior parietal lobule, between dorsomedial prefrontal cortex and ventromedial prefrontal cortex, and between ventromedial prefrontal cortex and right temporal cortex (reflecting reduced analytic evaluation, emotional appraisal, and retrieval or encoding of memories during self-referential processes, respectively). ${ }^{21,22}$ This empirical evidence is in line with our findings that maintaining regular practice of mindfulness meditation might be useful in promoting better mental health.

The present study has several limitations. In-depth assessment of meditation methods and mental and physical health of participants were not assessed. The crosssectional observational study design cannot determine any causal relationship between mindfulness meditation and mental health. The possibility of reverse causation cannot be excluded, as we did not assess the baseline mental health and health-related quality of life prior to the start of practising mindfulness meditation in their life. Sampling and recall biases might be present. Those who declined to be interviewed or those who secularised could potentially have poorer mental health and health-related quality of life. The number of years and the amount of time spent in mindfulness meditation were self-reported without verification. It is of interest to compare monastics who do not practise meditation regularly and secularised meditation practitioners with those who have regular practice in future studies. Our findings may not be applicable to people who practise mindfulness-based stress reduction, owing to differences in characteristics of the cohort and the form of mindfulness meditation.

\section{Conclusions}

Among Chinese Buddhist monastics who practise daily mindfulness meditation, spending more time each day and having longer years of practice were associated with better mental health. Further studies in the general populations, with a more comprehensive assessment of meditation methods, health outcomes, and underlying mechanisms might help ascertain the association between the amount of practice in mindfulness meditation and health benefits.

\section{Acknowledgements}

We thank the secretary general and abbot of the Tsz Shan Monastery for their permission of this study, and the participants who were not compensated for their contributions.

\section{Funding}

This was a self-initiated study and was not supported by any funding.

\section{Declaration}

The authors have no conflict of interest to disclose.

\section{References}

1. Rapgay L, Bystrisky A. Classical mindfulness: an introduction to its theory and practice for clinical application. Ann N Y Acad Sci 2009;1172:148-62. Crossref

2. Chiesa A. The difficulty of defining mindfulness: current thought and critical issues. Mindfulness 2013;4:255-68. Crossref

3. Thera N. The Heart of Buddhist Meditation. London: Rider; 1973.

4. Kabat-Zinn J. An outpatient program in behavioral medicine for chronic pain patients based on the practice of mindfulness meditation: theoretical considerations and preliminary results. Gen Hosp Psychiatry 1982;4:33-47. Crossref

5. Kabat-Zinn J. Full Catastrophe Living: Using the Wisdom of Your Body and Mind to Face Stress, Pain, and Illness. New York: Dell; 1990.

6. Kabat-Zinn J, Massion AO, Kristeller J, Peterson LG, Fletcher KE, Pbert L, et al. Effectiveness of a meditation-based stress reduction program in the treatment of anxiety disorders. Am J Psychiatry 1992;149:936-43. Crossref

7. Miller JJ, Fletcher K, Kabat-Zinn J. Three-year follow-up and clinical 
implications of a mindfulness meditation-based stress reduction intervention in the treatment of anxiety disorders. Gen Hosp Psychiatry 1995:17:192-200. Crossref

8. Ramel W, Goldin P, Carmona PE, McQuaid JR. The effects of mindfulness meditation on cognitive processes and affect in patients with past depression. Cognit Ther Res 2004;28:433-55. Crossref

9. Davidson RJ, Kabat-Zinn J, Schumacher J, Rosenkranz M, Muller D, Santorelli SF, et al. Alterations in brain and immune function produced by mindfulness meditation. Psychosom Med 2003;65:564-70. Crossref

10. Leung NT, Lo MM, Lee TM. Potential therapeutic effect of meditation for treating affective dysregulation. Evid Based Complement Alternat Med 2014;2014:402718. Crossref

11. Shi L, Zhang D, Wang L, Zhuang J, Cook R, Chen L. Meditation and blood pressure: a meta-analysis of randomized clinical trials. J Hypertens 2017;35:696-706. Crossref

12. Goyal M, Singh S, Sibinga EM, Gould NF, Rowland-Seymour A, Sharma R, et al. Meditation programs for psychological stress and well-being: a systematic review and meta-analysis. JAMA Intern Med 2014;174:357-68. Crossref

13. Carmody J, Baer RA. Relationships between mindfulness practice and levels of mindfulness, medical and psychological symptoms and wellbeing in a mindfulness-based stress reduction program. J Behav Med 2008;31:23-33. Crossref

14. Carmody J, Baer RA. How long does a mindfulness-based stress reduction program need to be? A review of class contact hours and effect sizes for psychological distress. J Clin Psychol 2009;65:627-
38. Crossref

15. Liang Y, Wang L, Yin X. The factor structure of the 12-item general health questionnaire (GHQ-12) in young Chinese civil servants. Health Qual Life Outcomes 2016;14:136. Crossref

16. Lam ET, Lam CL, Fong DY, Huang WW. Is the SF-12 version 2 Health Survey a valid and equivalent substitute for the SF-36 version 2 Health Survey for the Chinese? J Eval Clin Pract 2013;19:200-8. Crossref

17. Shaku F, Tsutsumi M, Goto H, Saint Arnoult D. Measuring the effects of Zen training on quality of life and mental health among Japanese monk trainees: a cross-sectional study. J Altern Complement Med 2014;20:406-10. Crossref

18. Verma G, Araya R. The effect of meditation on psychological distress among Buddhist monks and nuns. Int J Psychiatry Med 2010;40:4618. Crossref

19. Chiesa A, Malinowski P. Mindfulness-based approaches: are they all the same? J Clin Psychol 2011;67:404-24. Crossref

20. Barua A, Basilio MA. Buddhism in Hong Kong. https://www. academia.edu/207083/BUDDHISM_IN_HONG_KONG. Accessed 31 January 2019.

21. Taylor VA, Grant J, Daneault V, Scavone G, Breton E, Roffe-Vidal S, et al. Impact of mindfulness on the neural responses to emotional pictures in experienced and beginner meditators. Neuroimage 2011;57:152433. Crossref

22. Taylor VA, Daneault V, Grant J, Scavone G, Breton E, Roffe-Vidal S, et al. Impact of meditation training on the default mode network during a restful state. Soc Cogn Affect Neurosci 2013;8:4-14. Crossref 